Print ISSN: 2288-4637 / Online ISSN 2288-4645

doi:10.13106/jafeb.2020.vol7.no9.769

\title{
Empowering Poor-Households Women on Productive Economy Businesses in Indonesia*
}

\author{
Suminah SUMINAH ${ }^{1}$, Sapja ANANTANYU ${ }^{2}$
}

Received: June 28, 2020 Revised: July 12, 2020 Accepted: August 10, 2020

\begin{abstract}
Self-efficacy has been extensively evaluated, but no studies have investigated the effect of self-efficacy on the self-reliance of women in poor-households economic productivity. This study analyzes self-efficacy as a personal factor, learning processes, and social support as an environmental factor towards the achievement of self-reliance in women from poor-households in productive economy businesses. Despite the dominant logic of this scheme, there is a need for field-based data regarding whether the variable really supports the sustainable empowerment of poor-households women. This study used the quantitative method through the survey technique. The samples of this study included 250 people collected from five regencies in Indonesia by using a multiple-stage random sampling. The data were analyzed with structural equation modeling. The results show that social support has a significant positive impact on the learning process; social support has a direct negative impact on self-efficacy. The learning process has a direct positive influence on self-efficacy, while social support has a non-significant impact on self-reliance. The learning process has a direct influence on self-reliance. Social support and the learning process both have significant positive impact on self-efficacy. Social support, learning process, and self-efficacy simultaneously have a positive impact on self-reliance in productive economic activities.
\end{abstract}

Keywords: Social Support, Learning Process, Self-Efficacy

JEL Classification Code: D12, D14, G15

\section{Introduction}

Poverty is a problem faced by all countries, especially developing countries such as Indonesia. According to the National Family Planning Coordinating Board (BKKBN), low-income families include those in the "pre-prosperous family" stage and those in the "prosperous family stage I." Although poverty and sustainable women's empowerment

\section{*Acknowledgments:}

This article is part of the top research grant for Sebelas Maret University (UNS). The authors would like to thank Sebelas Maret University for funding this research through DIPA BLU UNS funds.

${ }^{1}$ First Author and Corresponding Author. Postgraduate Faculty, Universitas Sebelas Maret, Surakarta, Indonesia [Postal Address: JI. Ir. Sutami 36 Kentingan, Surakarta, Jawa Tengah, 57126, Indonesia] E-mail: sum_anan@yahoo.com

${ }^{2}$ Postgraduate Faculty, Universitas Sebelas Maret, Surakarta, Indonesia.

(c) Copyright: The Author(s)

This is an Open Access article distributed under the terms of the Creative Commons Attribution Non-Commercial License (https://creativecommons.org/licenses/by-nc/4.0/) which permits unrestricted non-commercial use, distribution, and reproduction in any medium, provided the original work is properly cited. are current buzzwords in development action and discourse globally, it is mostly in the global south that the critical issues remain most alarming and evident (Ekong, 1991; Izugbara \& Ukwayi, 2002; Mortimore, Adam, \& Harris, 2000). In Indonesia, the proportion of pre-prosperous families is as high as $20.86 \%$, while prosperous families I account for as much as $23.01 \%$ (BKKBN, 2014). In Central Java, the percentages of pre-prosperous and prosperous families are also much higher than the national percentages $(28.79 \%$ and $19.1 \%$, respectively) (BKKBN, 2014). Concerning poverty, women's empowerment programs are expected to contribute to poverty reduction. As proposed by Friedmann (1992), the empowerment approach is one of the policy approaches related to the position of women in development. McWhirter (1991) defines empowerment as the process by which people, organizations, or groups who are powerless (a) become aware of the power dynamics at work in their life context, (b) develop the skills and capacity for gaining some reasonable control over their lives, (c) exercise this control without infringing upon the rights of others, and (d) support the empowerment of others in the community. 
In Indonesia, a range of empowerment programs for poverty alleviation have been implemented, including the PWP (Women Productive Production Project), UPM (Microfinance Business Unit), P2KP (Urban Poverty Program, Ministry of Public Works) Prima Village (UPKP), UP2K (Family Income Improvement Effort from PKK), KUBe (Joint Business Group from the Department of Social Affairs), MFI Perkasa (Micro Finance Institution of Women Healthy and Prosperous Families from State Ministry for Cooperatives and Small and Medium Enterprises), KBU (Business Learning Group from Directorate General for Outside School Education, Ministry of National Education), and SPP program (Women Savings and Loans) as a national movement in mobilizing women's involvement in poverty reduction efforts. These programs are conducted to encourage interest, motivation, and improvement of knowledge and business skills as a learning process, providing social support to achieve self-reliance.

Self-reliance is one indicator of the development programs' success and can be influenced by personality and environment. Lewin (1942)'s theory served as the theoretical basis of this study, in which the behavior of people in a society is $B=f(P, E)$, meaning that behavior is a function of the individual's situation $(\mathrm{P})$ and environment $(\mathrm{E})$.

The learning process (as environment) is a process in which a person changes his or her knowledge, attitudes, and skills (Udin, Suharnomo, Rahardja, \& Handayani, 2019). The learning process that influences self-efficacy includes (1) direct experiences or enactive mastery experiences, (2) vicarious learning, (3) and verbal persuasion (Bandura, 1997a; Gibson et al., 2012a; Johnson \& Johnson, 2006; Sullivan \& Mahalik, 2000a). Furthermore, self-efficacy (as personality) is an essential element in a person's business success, as it corresponds to performance success and the beliefs and hopes of those who associate the business with the work.

The results showed that social support (as environment) is a manifestation of the social interactions that involve people in a system that is believed to provide love, affection, and attention from family, friends, professionals, informal leaders, and government (Nguyen, 2020). This social support may include emotional support, information support, instrumental support, esteem support, and networking or socializing support (Cohen \& Syme, 1985; McArthur, 2007; Sarafino \& Smith, 1998; Walker, 1993).

Problems of rural women are lack of access to better education, health, nutrition, water, and sanitation, burdensome, and economic (Lahiri-Dutt \& Samanta, 2002). Based on data from the Office of Women's Empowerment (2012), productive economic business programs have empowered as many as 363,121 people in poor households in Central Java. Based on the initial survey results, $12.14 \%$ of women included in the poor households' category carry out productive economic activities.
Allegedly, women in poor households who are engaged in productive economic activities have low self-reliance because there are positive psychological forces that provide reinforcement. Positive psychology is the study of conditions and processes that influence the development and optimization of the functions of individuals, groups, or institutions (Betz, 2007). One positive psychological approach that is considered to reveal the psychological aspects of a person's personality is oriented towards selfreliance and its alleged effect on the individual's performance of the individual, i.e., self-efficacy.

The theory of self-efficacy on which the present study is based is from Bandura. Bandura (1997b) states that self-efficacy is "beliefs in one's capabilities to mobilize the motivation, cognitive resources, and courses of action needed to meet given situational demands." Self-efficacy is a belief in one's ability to produce motivation, cognitive resources, and the series of actions or behaviors required to meet the demands of the situation at hand (Gibson et al., 2012b; Schultz \& Schultz, 1990; Gibson, Ivancevich, \& Donnelly, 2009; Stajkovic \& Luthans 1998). Self-efficacy is an essential element in a person's ability to successfully run a business, and it is fundamental to reach success and the beliefs and hopes of someone who associates business with work.

In recent years, studies on self-efficacy have been conducted in the fields of health, education, farmer groups, careers, and performance. Halim and Muttaqin (2014) and Michie and Nelson (2006) showed that the greater the coping self-efficacy, the greater the positive behavior. This finding relates to those reported by Schwarzer and Renner (2000), who indicated that higher levels of self-efficacy correspond to higher optimism regarding one's ability to change bad habits and a higher initiative to behave in healthy ways. Thomas et al. (2009) show that self-efficacy influences motivation in academic adjustments, such as regulated external motivation and identified motivation. Wang and Netemeyer (2002) state that self-efficacy influences performance. Kim (2019) and Ramdan (2011) suggest that self-efficacy and employee perceptions are positively related to employee safety performance and are accurate predictors of achievement. Wattimena (2009) shows that self-efficacy plays a significant positive role in prosperity. Tirta (2012) indicates that empowerment and self-efficacy have a positive and significant influence on performance and that self-efficacy moderates the influence of empowerment on performance. Hariadi (2011) states that in groups of farmers, group members with high self-efficacy will be more active and display stronger effort towards achieving group goals. Walumba et al. (2008) stated that individuals with high self-efficacy would have confidence in their ability to complete their work. No study has examined self-efficacy as a force to increase women's self-reliance in productive 
economic enterprises. The present study analyzes the selfefficacy associated with women's self-reliance in productive economic enterprises in five regencies in Central Java using quantitative methods with SEM analysis.

From various viewpoints on the concept of empowerment, the concept of abstracted empowerment is used in this study as a means of supporting the local economy through strengthening factors of production, the control of distribution and marketing, community income, and public access to information, knowledge, and skills. This approach should be conducted from multiple perspectives, including from that of the community and policy (Bryant \& White, 1987; Christenson \& Robinson, 1989; Ife \& Tesoriero, 2008; Kartasasmita, 1996; Page \& Czuba, 1999; Purnomo, Rahayu, Riani, Suminah, \& Udin, 2020; Rothman, Erlich, \& Tropman, 1996).

Based on the above literature review and theoretical foundations, the relationship between variables is illustrated in the framework in Figure 1. It shows some hypotheses as follows: (1) social support variables have direct and significant influence on the learning process, self-efficacy, and self-reliance; (2) the learning process directly influences self-efficacy and self-reliance, while self-efficacy influences self-reliance; (3) social support and learning processes have simultaneous influence on self-efficacy; (4) social support, learning processes, and self-efficacy have simultaneous effects on self-reliance.

\section{Research Methods}

This study explains the various relationships of social interaction phenomena in the community. A quantitative method with survey techniques was used, and qualitative information was included to understand the study's concepts better and ensure the accuracy of the quantitative results. The samples were taken through a multiple-stage random sampling, and 250 women in poor households engaged in productive economic activities from 80 villages from five regencies in Central Java Indonesia were selected.

The primary data include social support, learning processes, self-efficacy, and self-reliance of women in poor households engaged in productive economic activities. These data were collected through interviews and direct field observation. Validity and reliability tests with Cronbach's alpha coefficients were conducted after arranging the questionnaire, as shown in Table 1. In this study, the measurement device was a subject-oriented scale, as suggested by Torgeson (Azwar, 2009). The data on the before mentioned variables were measured as interval scores on a Likert scale.

The result of the instrument validity test with Cronbach's alpha coefficients shows that five of 309 statements were invalid. These were removed from the questionnaire, leaving 304 valid items. In the analysis of structural equations in this study, starting from determining the latent constructs with confirmatory factor analysis (CFA) and fulfilling the assumptions of the structural equation model, it was necessary to obtain an acceptably fitting model by testing the reliability of the construct, the normality test, and the multicollinearity test using CFA. The model connects to exogenous and endogenous variables to become a structural equation model and test the goodness of fit of the chi-square value, probability, RMSEA (root mean square error of approximation), GFI (goodness of fit index), AGFI (adjusted goodness of fit index), NFI (normed fit index), CFI (comparative fit index), and CMIN/DF (minimum sample discrepancy function divided by degrees of freedom) with a cut of a determined value (Ghozali, 2011; Hair et al., 2006).

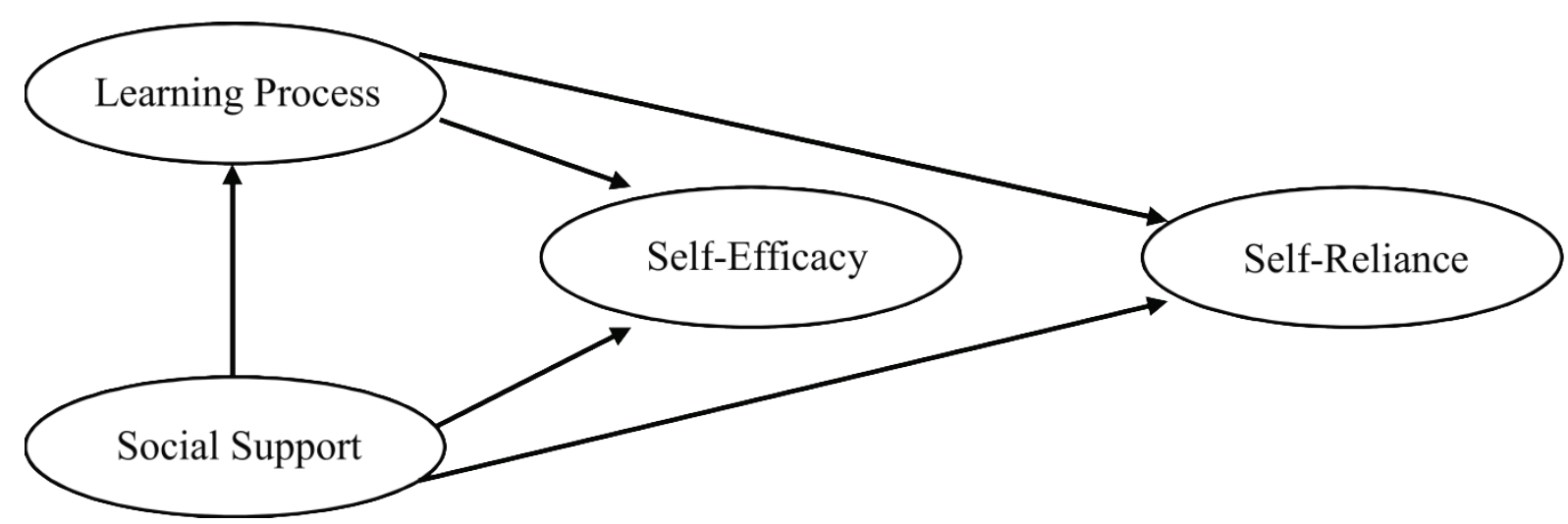

Figure 1: Research Framework 
Table 1: The Results of the Reliability of the Research Instrument

\begin{tabular}{|l|c|c|}
\hline Construct Variable & Cronbach's Alpha & Interpretation \\
\hline Social support supported by the manifest variable: & & \\
\hline Family support (DUKEL) & 0.949 & Reliable \\
\hline Peer support (DUTEM) & 0.947 & Reliable \\
\hline Women empowerment officer support (DUPET) & 0.937 & Reliable \\
\hline Leader support (DUPEM) & 0.963 & Reliable \\
\hline Support of other institutional actors (DULGL) & 0.938 & Reliable \\
\hline Learning process supported by the manifest variable: & & Reliable \\
\hline Direct learning (BELANG) & 0.817 & Reliable \\
\hline Learning from others (BEORLA) & 0.920 & Reliable \\
\hline Learning from verbal persuasion (BEBUJL) & 0.929 & Reliable \\
\hline Self-efficacy supported by the manifest variable: & & Reliable \\
\hline Self-efficacy in running a business (MELAK) & 0.820 & Reliable \\
\hline Maintaining business (MEPERT) & 0.838 & Reliable \\
\hline Developing business (MENGM) & 0.794 & Reliable \\
\hline Self-reliance supported by the manifest variable: & & Reliable \\
\hline Self-reliance to overcome problems (MGTS) & 0.842 & Reliable \\
\hline Self-reliance to adjust to the environment (MNYS) & 0.788 & \\
\hline Self-reliance in utilizing resources (MMFT) & 0.751 & 0.787 \\
\hline Self-reliance to make decisions in business (MGKTR) & & \\
\hline
\end{tabular}

\section{Results}

The results of the analysis of the measurement model using CFA (confirmatory factor analysis) of each latent variable (constructs) were developed through observation. This condition shows that the latent social support conforms to the test model (goodness of fit test) with a chi-square value of 2,989 and a degree of probability of 0.702 . The latent learning process also conforms to a model fit chi-square value of 1,421 and a probability level of 0.167 . Similarly, latent self-efficacy also conforms to a model fit chi-square value of 1,226 and a probability level of 0.221 . The latent self-reliance conformity qualifies with a model fit chi-square value of 2,118 and a probability level of 0.349 . The fourth latent variable consists of 15 observation items, only one of which (observed family support) has an observed valueloading factor below 0.30 .

The results of reliability tests of the theoretical constructs returned latent value estimates with standardized loadings above 0.50 : social support $=0.68$; learning process $=0.79$; self-efficacy $=0.89$; and self-reliance $=0.90$. The results showed variance extracted values from all four constructs above 0.30: the construct of social support $=0.31$; the learning process $=0.56$; self-efficacy $=0.74$; and self-reliance $=0.68$. By squaring the results' values, we observe considerable variation with high explanatory power.

The results of normality test and multicollinearity test show the previous critical ratio (c.r.) Kurtosis value was above 2.58 (it was not normal), but after detecting the process toward the outliers, which was shown by the value of Mahalanobis distance and centroid score, the c.r. Kurtosis value decreased between -2.58 up to 2.58 , it was 2.478 (it was normal). The multicollinearity test showed that all latent variables (social support, learning process, self-efficacy, self-reliance) were free of multicollinearity and had values below 0.80 , which means that there was no high correlation so that further tests could be done. The results of the model test using CFA originally showed that the model was not fit, with a chi-square value of 212,503 and a probability level of 0.000 . The model was modified using the facility modification index (MI) and removing the many observed variables with high error values. Modified test results are presented in Figure 2.

Figure 2 shows the modified measurement model with an analysis of the CFA was fit, with a chi-square value of 35.43 and a probability level of 0.191 . CFA test results were then drawn and analyzed, with a line influencing the structural model, as shown in Figure 3. 


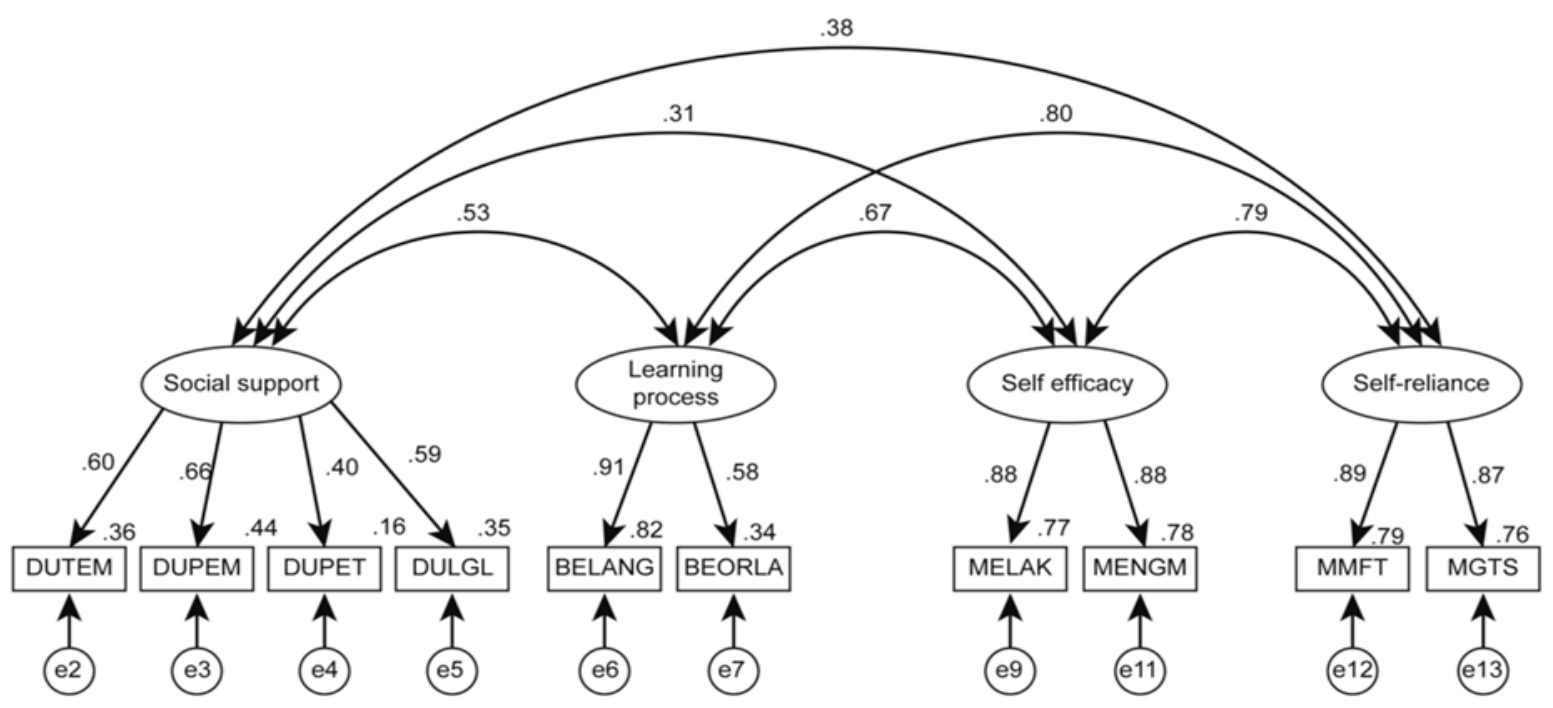

Figure 2: The Results of Modified Confirmatory Analysis

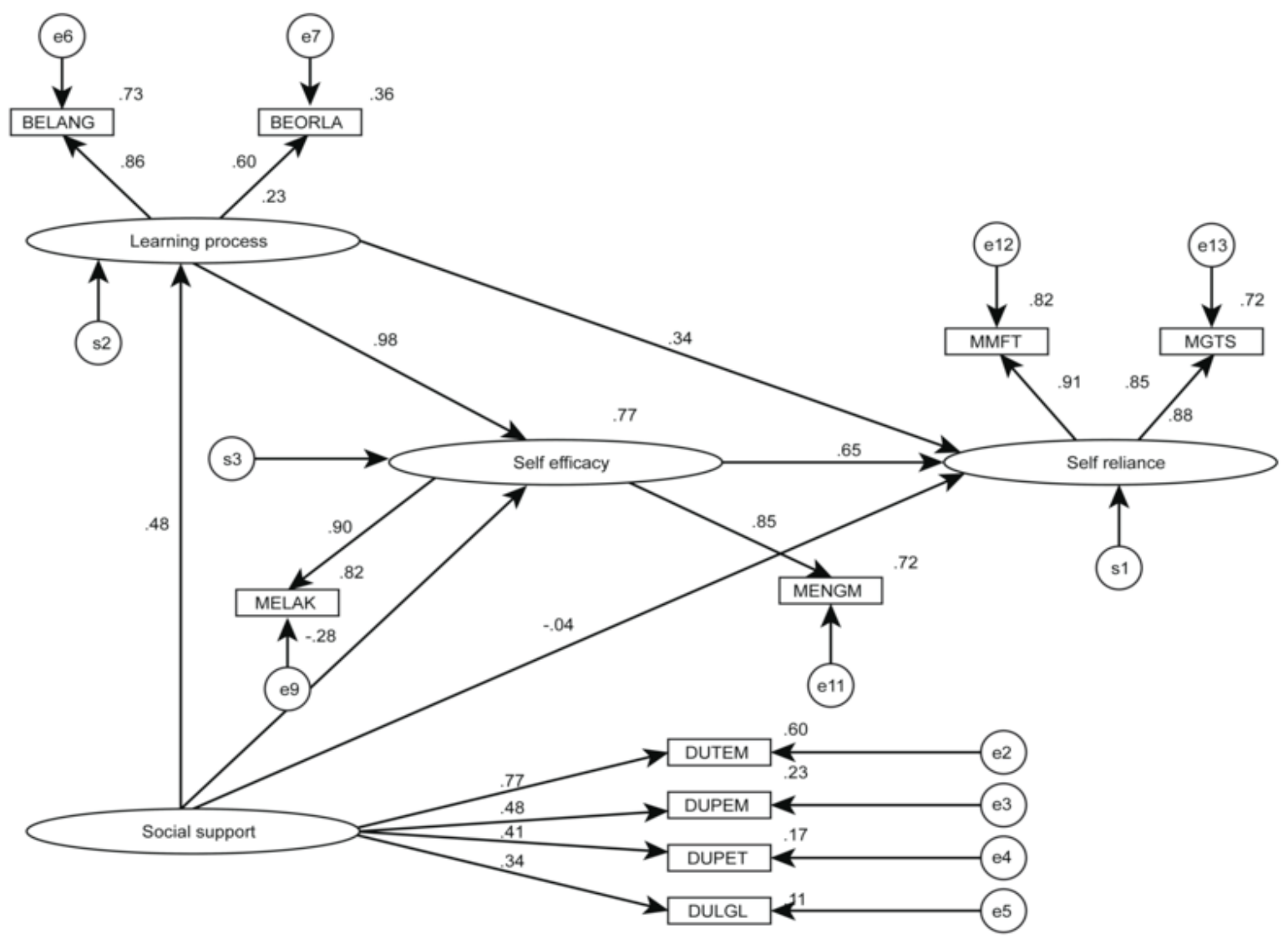

Figure 3: The Results of Modified Structural Model 
Table 2: Test Results of the Modified Structural Model

\begin{tabular}{|l|c|c|c|}
\hline Criteria Goodness of Fit Index & Cut-off Value & Empirical Results & Model Evaluation \\
\hline Chi-squared & $<39.17$ & 27.66 & Fit \\
\hline Probability & $>0.05$ & 0.536 & Fit \\
\hline CMIN/DF & $<2.00$ & 0.010 & Fit \\
\hline GFI & $>0.90$ & 0.976 & Fit \\
\hline AGFI & $>0.90$ & 0.954 & Fit \\
\hline CFI & $>0.95$ & 0.956 & Fit \\
\hline NFI & $>0.90$ & 0.972 & Fit \\
\hline TLI & $>0.90$ & 0.992 & Fit \\
\hline RMSEA & $<0.08$ & 0.019 & Fit \\
\hline
\end{tabular}

Table 3: Test Result of Standardized Regression Weights on Modified Structural Model

\begin{tabular}{|l|c|c|c|c|}
\hline Correlation between the Variables & Estimate & Estimation Standardized & Critical Ratio & Prob. \\
\hline Learning process <-- Social support & 2.142 & 0.479 & 3.374 & $* * *$ \\
\hline Self-efficacy <-- Learning process & 0.881 & 0.979 & 7.712 & ${ }^{* * *}$ \\
\hline Self-efficacy <-- Social support & -1.136 & -0.283 & -2.439 & $0.015^{* *}$ \\
\hline Self-reliance <-- Learning process & 0.383 & 0.337 & 2.474 & $0.013^{* *}$ \\
\hline Self-reliance <-- Self-reliance & 0.814 & -0.039 & 3.565 & ${ }^{* * *}$ \\
\hline Self-reliance <-- Social support & -0.199 & 0.645 & -0.421 & $0.673^{\text {NS }}$ \\
\hline Note: ${ }^{* *}$ ) significant on alpha $=0.05 ;{ }^{* * *}$ ) significant on alpha $=0.01 ;$ NS) non-significant; Prob.) probability \\
\hline
\end{tabular}

The test results show the modified structural model in compliance with the conformance test model or goodness of fit test in Table 2, and the influence among the latent variables is shown in Table 3. The result of the model in the Figure 3 test is fit or not, it can be seen in Table 2. Then, after the results of the Modified Structural Model indicate the Fit model, it was continued to do the Standardized Regression Weights test to know the influence among latent variables.

In Table 3 and Figure 3 above, it can be explained that the effect of linkages between latent variables as follows: social support has a direct positive impact, which is very significant for the learning process. Social support has a direct and significant negative impact on self-efficacy, while social support has a non-significant effect on self-reliance. Therefore, social support can greatly and directly improve the learning process but cannot increase self-reliance and may even decrease the self-efficacy of women in poor households engaged in productive economic activities.
The learning process has a direct positive effect on selfefficacy that is very significant, but it has a non-significant effect on self-reliance. Self-efficacy has a direct, significantly positive effect on self-reliance.

Social support and learning processes both have significant positive effects on self-efficacy, with a contribution of 0.77 . This can explain why social support and learning processes can simultaneously improve the self-efficacy of women in poor households engaged in productive economic activities.

Social support, learning processes, and self-efficacy all positively contribute to the self-reliance of women in poor households engaged in productive economic activities, with a value of 0.88 . These women's self-reliance in productive economic activities can reach higher/maximum results if social support and learning processes are available through the mediator of self-efficacy more often than they are available directly without mediation. In other words, the analysis shows that indirect effects are highest when social support is given through the learning process and self-efficacy. 


\section{Discussion}

\subsection{The Effect of Social Support on the Learning Process}

The results of this study indicate that social support has an influence on the learning process. Social support, consisting of family support, peer support, leader support, women's empowerment support, and support of other institutions, can improve the learning processes that include learning from one's own experience and learning from the experiences of others. The higher the social support, the higher the learning process will be. The results of this study support the results of Steinberg's research (2002), which reveals that family is a source of social support because the family creates trusting relationships. Family support plays an important role in academic success (Berns, 2007). In East Asian societies such as Korea, there is an assumption that the family is a means or source of support that can motivate children to achieve success in the education field (Kim \& Park, 2008). Gullotta and Adams (2005) suggest that a lack of social support can be identified as an obstacle to achievement. The results of research by Eamon (2005) reveal that students in Latin America consider the existence of particular factors in their social environment, such as parents, neighbors, friends, and school, to be sources of success. The same perspective appeared in Italy, which shows that teachers could function as media in achieving success in the education field, where they gave informational support (Matteucci, 2007).

\subsection{The Effect of Social Support on Self-Efficacy}

The results of this study revealed that social support has a significant negative effect on self-efficacy, which means that higher social support given to women in poor households corresponds to decreased self-efficacy. This correlation may exist because of appropriate materials or materials that did not meet the women's needs or because of appropriate methods in giving support. The support given was only in the form of suggestions, advice, solicitation, and charity, and did not include concrete learning experiences. When given inappropriate support for their needs, women may be unsure whether they will succeed in implementing or developing their business, and their self-efficacy will decrease. The results of this study are not in accordance with the finding of Chlebowy and Garvin (2006) that social support influences the self-efficacy of patients with diabetes. Similarly, the results of Gultom and Hastjarjo (2012) indicate a significant relationship between self-efficacy of persons with physical disabilities and social support in orphanages and institutions. Theoretically, the correlation between social support and self-efficacy can be understood from the perspective of Rodin and Salovey (1989), who view that, through social support, a person will have a positive experience and increase her or his confidence so that she or he will be able to control any changes in the surrounding environment.

\subsection{The Effect of Social Support on Self-Reliance}

This study shows that social support has no significant direct effect on self-reliance. The support given to women in poor households running their own businesses was in the form of training, counseling, solicitation, and suggestions, which require more cognitive ability and are not preferred by the women. In addition, their low participation in training was not merely caused by the materials' content, but also by a sense of "pekewuh", or discomfort with those who invited them. Other support came in the form of charity for business capital and production equipment, which made the women dependent on other parties because, in Javanese culture, the more supported they are, the more dependent they will be. They will be more "ayem, nyagerke", or dependent, and will not want to make any effort. Thus, many subjects who were given substantial support to run their businesses ultimately expressed low independence if they were not supported sufficiently by learning outcomes through direct experience and observing the experience of others. Low levels of social support cannot directly improve the self-reliance of women in poor households engaged in productive economic business. The results of this study are not in accordance with Gottlieb's finding (1983) that the existence of high social support encourages individuals to be more active and independent in entrepreneurship because social support provides more positive effects than negative effects. As Soemanto (1993) explained, low self-reliance is due to low social support, which makes an individual view work as a burden such that he or she feels lazy about making an effort.

\subsection{The Effect of Learning Processes on Self- Efficacy}

In this study, learning processes were shown to have a significant effect on the self-efficacy of women in poor households engaged in productive economic business. Arstein (1969) argues that all participants must acknowledge the degree of citizen empowerment in a working relationship. Rubin and Rubin (1986) point out that empowerment is one of the important concepts in community work. The goals of empowerment are actually in line with the philosophies of community work, which emphasize people's power and participation, the raising of people's social consciousness, and the changing of the environment to eliminate the social constraints acting on people's lives. The results of this study should be informative for related parties who have an interest in empowering women in poor households who are engaged in productive economic endeavors. Improving 
self-efficacy through understanding the importance of learning outcomes from direct experience and observing the experiences of others is in line with Baron and Byrne (1997), who explain that there are two factors that influence self-efficacy as a learning process: (1) direct experience, as a result of the experience of doing a task in the past; (2) indirect experience, as a result of observing the experiences of others. This concept is in line with the theory of Sullivan and Mahalik (2000b), which states that achievement, others' experiences, verbal persuasion, and emotional states play important roles in developing self-efficacy. These factors are important because when someone sees someone else achieving success, they will try to follow in the footsteps of her or his success.

\subsection{The Effect of Learning Processes on Self- Reliance}

Learning processes have no significant effect on the self-reliance of women in poor households engaged in productive economic business. Time was when we all thought that economic development would somehow trickle down to the poor and dispossessed and lift them out of their misery. This thinking has proved tragically unfounded (Eade \& Ligteringen, 2001). This condition can be explained by showing that such women can not only be verbally persuaded, but also encouraged to gain direct experience through, for example, participation in competitions or fairs, which will increase their self-reliance and improve their independence. In addition, they can be given examples from the direct experience of other people who have achieved success in running businesses, such as through internship programs or comparison studies. This explanation supports the research by Crow and Crow (1963), who state that selfreliance is neither innate nor acquired from birth but, rather, appears and changes along with experience.

\subsection{The Effect of Self-Efficacy on Self-Reliance}

The results of this study indicate that self-efficacy has a very positive and significant direct effect on self-reliance. This finding is in accordance with the opinions expressed by St-Jean and Audet (2009) that self-efficacy gives influence to an entrepreneur. Self-efficacy is mentioned as one of the factors that affect one's self-reliance in running his or her business. Someone with high self-efficacy will always survive. With high confidence, a person will be ready to face all obstacles during the entrepreneurship process. Many studies show that self-efficacy is related to career development. As explained above, self-efficacy plays an important role in determining motivation and self-reliance in entrepreneurship, as low self-efficacy will not deter someone from taking action. Boyd and Vozikis (1994) explain that self-efficacy is an influential element in the formation of an entrepreneur. The self-efficacy of women in poor households will influence their achievement of self-reliance in productive economic business.

\subsection{The Effect of Social Support and Learning Process Simultaneously Influence Self-Efficacy}

In this study, social support and learning processes both have a positive and significant effect on self-efficacy. Both social support and learning process, which consists of peer support, leader support, support of women's empowerment staff, and support of other institutions, and learning processes consisting of direct learning experience results, that is, the learning resulting from others' experiences, contribute to improve self-efficacy, which consists of the self-confidence to develop and carry out productive economic businesses, as seen in as much as $77 \%$ of women in poor households. This finding is relevant to the results of Bandura's (1989a) study, showing that self-efficacy can be influenced through social support such as positive emotional support, positive words of encouragement, and positive persuasion, as well as successful examples of known people and experiences in task mastering. Furthermore, Bandura (1989b) also explained that learning processes could affect self-efficacy.

\subsection{The Effect of Social Support and Learning Processes Done with Self-Efficacy}

In this study, social support, learning processes, and selfefficacy together contributed to $88 \%$ of the improvements in the self-reliance of women in poor households engaged in productive economic business. From the scientific perspective, the present authors criticize the theory of Kurt Lewin used as the foundational theory. Lewin states that the behavior of individuals is influenced by personality and environment, presenting the basic equation of human behavior $B=f(P, E)$. It was not explained in detail whether the effect is direct or indirect, nor whether the direction of its influence is positive or negative. The theoretical findings in the present study show that not all environments directly affect the self-reliance behavior of women in poor households engaged in productive economic business. For example, social support has a tendency to decrease the selfefficacy of women in poor households who are running businesses. Social support will have a significant effect on the self-reliance of women in poor households running a productive economic business if it is given through direct learning processes or from the experience of others, such as via an apprenticeship program with similar businesses that have been successful or by direct observation of others who have a successful similar business. Thus, self-efficacy can be increased, followed by an improvement of self-reliance. 


\section{Conclusion}

Social support has a positive and significant impact on the learning process. Social support has a direct and negative influence on self-efficacy. The learning process has a direct positive influence on self-efficacy, while social support has an on-significant effect on self-reliance. The learning process has a direct influence on self-reliance. Social support and learning processes both have a positive and significant effect on self-efficacy. Together, these factors contribute as much as $77 \%$ in the increase of self-efficacy of poor household women. Social support, learning processes, and self-efficacy simultaneously give positive contributions to the self-reliance of women in poor households engaged in productive economic activities, with a value of $88 \%$. These women's self-reliance in productive economic activities can be maximized if social support, learning processes, and selfefficacy are given through sustainable empowerment for poor-households women.

\section{References}

Azwar, S. (2009). Preparation of Psychology Scale. Yogyakarta, Indonesia: Student Library. [Indonesian]

Bandura, A. (1997). Self Efficacy: The Exercise of Control (pp.79-115). New York, NY: WH Freeman and Company.

Bandura, A. (1989). Human Agency in Social Cognitive Theory. American Psychologist, 44(9), 1175-1184. doi: 10.1037/0003-066X.44.9.1175

Baron, R. A., \& Byrne, D. (1997). Social Psychology. Boston, MA: Bacon.

Berns, R. M. (2007). Child, Family, School, Community: Socialization and Support $\left(7^{\text {th }}\right.$ ed.). Belmont, CA: Thompson Wadsworth.

Betz, N. E. (2007). Career Self Efficacy: Exemplary Recent Research and Emerging Direction. Journal of Career Assessment, 15(4), 403-422. doi: 10.1177/1069072707305759

BKKBN. (2014). Profile of 2013 Family Data Collection Results, National Family Planning Coordinating Board. Jawa Tengah, Indonesia: BKKBN Press. [Indonesian]

Boyd, N.G. and Vozikiz, G.S. (1994). The Influence of Self Efficacy on the Development of Entrepreneurial Intentions and Actions, Entrepreneurship Theory and Practice, 18(4), 63-77, doi: 1042-2587-94-184

Bryant, C., \& White, L. G. (1987). Development Management for Developing Countries. Jakarta: LP3ES Press. [Indonesian]

Chlebowy, D. O., \& Garvin, B. J. (2006). Social Support, Self Efficacy, and Outcome Expectations: Impact on Self Behaviors and Glycemic Control in Caucasian and African American Adult with Type 2 Diabetes, Journal of Health Psychology, 29, 17-24. doi: 10.1177/1359105306066610
Christenson, J. A., \& Robinson, J. W. Jr. (1989). Community Development in Perspective (pp. 212-301). Iowa City, IA: Iowa State University Press.

Cohen, S., \& Syme, S. L. (Eds.). (1985). Social Support and Health. Cambridge, MA: Academic Press.

Crow, L. D., \& Crow, A. (1993). General Psychology. Heights, OH: Littlefield Adam and Co.

Eade, D., \& Ligteringen, E. (2001). NGOs and the future: taking stock, shaping debates, changing practice. In D. Eade and E. Ligteringen (eds.), Debating Development, London, UK: Oxfam GB. (pp. 11-18). doi: 10.3362/9780855986858.001

Eamon, M. K. (2005). Social Demographic, School, Neighborhood, and Parenting Influences on the Academic Achievement of Latino Young Adolescents, Journal of Youth and Adolescence, 34(2), 163-174. doi: 10.1007/s10964-005-3214-x

Ekong, E. E. (1991). Rural Development and the Persistence of Poverty in Nigeria. Inaugural Lecture Series No. 1. Calabar, Nigeria: University of Cross River State.

Friedman, J. (1993). Empowerment: The Politics and Alternative Development. Hoboken, NJ: Blackwell.

Gibson, J. L., Ivancevich, J. M., \& Donnelly, J.H. (2009). Organizations: Behavior, Structure, Processes. Burr Ridge, IL: Irwin.

Ghozali, I. (2011). Multivariate Analysis Application with the IBM-SPSS 19 Program. Semarang, Indonesia: Undip Press. [Indonesian]

Gottlieb, B. H. (1983). Social Support Strategies: Guidelines for Mental Health Practice. London, UK: Sage Publications.

Gullotta, T. P., \& Adams, G. R. (2005). Handbook of Adolescent Behavioral problem: Evidence-Based Approaches to Prevention and treatment. A Sponsored Publication of the Child and family Agency of Southeastern Connecticut, Springer Science Business, Media. Inc. doi: 10.1007/97814899749766

Gultom, M. S. R. (2012). Self-Efficacy of Early Adult Disabled Persons Fostered in the Institution Judging from Social Support and Perception of Vocational Rehabilitation. Doctoral dissertation. Yogyakarta, Indonesia: Universitas Gadjah Mada. [Indonesian]

Hair, J. F., Black, W. C. Babin, B. J., Anderson, R. E., \& Tatham, R. L. (2006). Multivariate Data Analysis (6 ${ }^{\text {th }}$ ed.). Upper Saddle River, NJ: Prentice-Hall International.

Halim, R. E., \& Muttaqin, F. (2014). The Effect of Warning Labels on Cigarette Packages: Textual vs. Textual-Visual and Self-Efficacy. Journal of Asian Finance, Economics and Business, 1(2), 25-30. doi: https://doi.org/10.13106/jafeb.2014.vol1.no2.25

Hariadi, S. S. (2011). Group Dynamics: Theory and Its Application for Analysis of the Success of Farmer Groups as Learning, Collaboration, Production and Business Units. Doctoral dissertation. Yogyakarta, Indonesia: Gadjah Mada University. [Indonesian] 
Ife, J., \& Frank, T. (2008). Community Development: Alternative Community Development in the Era of Globalization. Yogyakarta, Indonesia: Student Library. [Indonesian]

Izugbara, C. O., \& Ukwayi, J. (2002). Conceptual issues in Nigeria's Gender-Specific Rural Poverty Alleviation Strategy, Development in Practice, 12(1), 81-85. doi: 10.1080/096145202317215507

Johnson, D. W., \& Johnson, E. P. (2000). Joining Together: Group Theory and Group Skills. Upper Saddle River, NJ: PrenticeHall Inc.

Kartasasmita, G. (1996). Development for the People: Integrating Growth and Equality. Jakarta, Indonesia: Cides. [Indonesian]

Kim, J.-E. (2019). The Impact of Creative Role Identity and Creative Self-Efficacy on Employee Creativity in the Hotel Business. Journal of Asian Finance, Economics and Business, 6(2), 123-133. doi: https://doi.org/10.13106/jafeb.2019.vol6.no2.123

Kim, U., \& Park, Y. S. (2008). Cognitive, Relational, and Social Basic of academic Achievement in Confucian Cultures: Psychological, Indigenous, and Cultural Perspectives. In: Sorrentino, R.M., \& Yamaguchi, S (Eds.), Handbook of Motivation and Cognition across Culture. Oxford, UK: Elsevier Inc.

Lahiri-Dutt, K., \& Samanta, G. (2002). State Initiatives for the Empowerment of Women of Rural Communities: Experiences from Eastern India, Community Development Journal, 37(2), 137-156. doi: 10.1093/cdj/37.2.137

Lewin K. (1942). Field theory and learning, Year book of the National Society for the Society for the Study of Education (pp. 215-242), Chicago, IL: University of Chicago Press.

Matteucci, M. C. (2007). Teachers Facing School Failure: The Social Valorization of Effort in the School Context. Social Psychology of Education, 10(1), 29-53. doi: 10.1007/s11218006-9011-x

McArthur, C. T. (2007). Social Support \& Social Conflict. Retrieved January 10, 2020 from: http://hsr.e-contentmanagement.com/ archives/

McWhirter, E. H. (1991). Empowerment in counseling, Journal of Counseling and Development, 69, 222-227. doi: 10.1002/ j.1556-6676.1991.tb01491.x

Michie, S., \& Nelson, D. L. (2006). Barriers Women Face in Information Technology Careers (Self Efficacy, Passion and Gender Biases), Journal Woman in Management Review, 21(1), 10-27. doi: org/10.1108/09649420610643385

Mortimore, M., Adams, W., \& Harris, F. (2000). Poverty and Systems Research in the Dry Lands, Gatekeeper Series No. 94. https://www.jstor.org/stable/resrep01734

Nguyen, T. T. (2020). The Impact of Place Attractiveness and Social Supports on Internal Return Migration. Journal of Asian Finance, Economics and Business, 7(5), 305-314. doi: https://doi.org/10.13106/jafeb.2020.vol7.no5.305
Page, N., \& Czuba, C. E. (1999). Empowerment: What is It? Journal of Extension, 37(5). https://www.joe.org/joe/1999october/ comm1.php/

Purnomo, S., Rahayu, E. S., Riani, A. L., Suminah, S., \& Udin, U. (2020). Empowerment Model for Sustainable Tourism Village in an Emerging Country. The Journal of Asian Finance, Economics and Business, 7(2), 261-270. doi: https://doi. org/10.13106/jafeb.2020.vol7.no2.261

Ramdan, I. M. (2011). Self-Efficacy, Control Centers, and Workers' Perception as Predictors of Achieving Health and Safety Achievement. Kesmas: National Public Health Journal, 5(2), 56-63. http://journal.fkm.ui.ac.id/kesmas/article/view/149 [Indonesian]

Rodim, J., \& Salory, P. (1989). Health Psychology, Annual Review of Psychology, 40. doi: 10.1146/annurev.ps.40.020189.002533

Rothman, J., Erlich, J. L., \& Tropman, J. E. (1995). Strategies of Community Intervention (pp. 195-204). Itasca, IL: F.E. Peacock Publishers.

Rubin, H. J., \& Rubin, I. (1986). Community Organizing and Development. Princeton, NC: Merill Publishing Company.

Sarafino, E. P. (1998). Health Psychology: Biopsychososial Intervention ( $3^{\text {rd }}$ ed.). Hoboken, NJ: John Willey and Sons Inc.

Schultz, D. P., \& Schultz, S. E. (1990). Psychology and Industry Today: An Introduction to Industrial and Organizational Psychology $\left(5^{\text {th }}\right.$ ed.). New York, NY: Maxwell Macmillan International.

Schwarzer, R., \& Renner, B. (2000). Social Cognitive Predictors of Health Behavior: Action Self Efficacy and Coping Self Efficacy, Health Psychology, 19, 487-495. doi:10.1177/1359105309360071

Soemanto, W. (1993). Entrepreneurship Education. Jakarta, Indonesia: Bina Akasara. [Indonesian]

Stajkovic, A., \& Luthans, F. (1998). Social cognitive theory and selfefficacy: Going beyond traditional motivational and behavioural approaches, Organizational Dynamics, 26(4), 62-74.

Steinberg, L. (2002). Adolescence (6th ed.). New York, NY: McGraw-Hill.

St-Jean, S. E., \& Audet, J. (2009). Factors Leading to Satisfaction in a mentoring Scheme for Novice Entrepreneurs, International Journal of Evidence Based Coaching and Mentoring, 7(1), 115-148.

Sullivan, K. R., \& Mahalik, J. R. (2002). Increasing Career Self Efficacy for Women: Evaluating and Group Intervention, Journal of Counseling and Development, 78, 54-62. doi:10.1177/0011000011406452

Tirta, F. I. (2012). Analysis of the Effect of Empowerment on Increasing Employee Performance with Self Efficacy as Moderation Variables. Master thesis. Yogyakarta, Indonesia: Gadjah Mada University. [Indonesian] 
Thomas, D. M., Love, K M., Roan-Belle, C., Tyler, K. M., Brown, C. L., \& Garriott, P. O. (2009). Self-Efficacy, Motivation, and Academic Adjustment Among African American Women Attending Institutions of Higher Education, The Journal of Negro Education, 78(2), 159-171.

Udin, U., Suharnomo, S., Rahardja, E., \& Handayani, S. (2019). The Effect of Organizational Learning, IT Capability and Employee Adaptability on Job Performance: A Moderation Model. Espacios, 40(42), 1-11. doi: https://www.revistaespacios.com/ a19v40n42/19404225.html

Walker, M. E, Wasserman, S., \& Wellman, B. (1993). Statistical Models for Social Support Network. Sociological Methods and Research, 22(1), 71-98. https://doi. org/10.1177/0049124193022001004
Walumba, F., Avalio, B. J., \& Zhu, W. (2008). How Transformational Leadership Weaves Its Influence On Individual Job Performance: The Role of Identification and Efficacy Beliefs, Personnel Psychology, 61, 793-825.

Wang, G., \& Netemeyer, R. (2002). The Effects of Job Autonomy, Customer Demandingness, and Trait Competitiveness on Salesperson Learning, Self Efficacy and Performance, Journal of the Academy of Marketing Science, 30(3), 217-228. doi:10.1177/0092070302303003

Wattimena, I. (2009). The Role of Self-Efficacy and Virtue against Welfare in Women Contraception Users with Stress Mediation Due to Side Effects. Doctoral dissertation. Yogyakarta, Indonesia: Gadjah Mada University. [Indonesian] 